\title{
The Czech Crown Money Market as the Source for Pricing Customer Cash Products
}

\author{
Dušan Staniek*
}

\begin{abstract}
:
The paper examines the Czech crown money market in terms of products and volumes traded. The interest rate time series for the last 10 years are surveyed, and a parsimonious model is used to investigate to what extent the marketplace serves as the starting point for pricing customer cash products. Although satisfactory longterm relationships are observed, market disruptions are breaking up the assumed coherence. Special attention has to be paid to the decoupling of official fixing rates (PRIBOR) and real market rates in the current low interest rate environment.
\end{abstract}

Key words: Money market; Interest rate pass-through; PRIBOR.

JEL classification: E43, E50, G21, C20.

\section{Introduction}

The selection of the proper yield curve and the accurate interest rate for pricing financial products has become a challenge since the onset of the global financial crisis in summer 2007. A multiple-curve framework has developed, with interest rates formed by a set of basis adjustments and risk premiums. ${ }^{1}$

Yet the money market remains the marketplace where interest rates originate. Special attention has to be paid to the creation of the official fixing rates as the starting point for further yield curve construction and as the basis for setting the interest rate in customer products.

The composition of this paper is organized as follows. Section 2 reviews the Czech crown money market in terms of the products and volumes traded. Section 3 examines the pass-through mechanism from the main policy rate to the market and onwards into the rates quoted to the bank customers. Section 4 summarizes and presents concluding remarks.

* Dušan Staniek; University of Economics in Prague, Faculty of Finance and Accounting, Department of Banking and Insurance, Winston Churchilla Square 4, 13067 Prague 3, Czech Republic, <xstad05@vse.cz>.

This paper has been prepared with the financial support of a grant for Advanced methods of financial asset returns and risks modelling, IGA VŠE F1/23/2015, which the author gratefully acknowledges.

1 For more reading on curve decoupling see Bianchetti (2010), and Baran and Witzany (2014) for more on Czech discount curve construction. 


\section{Interbank market}

In this section we will focus on the basic interest rate products traded on the Czech money market. Cash products are represented by T-Bills, deposits ${ }^{2}$, repos, FX swaps and cross currency interest rate swaps (with exchange of notionals), while the derivatives are represented by forward rate agreements (FRA) and interest rate swaps (IRS, including overnight index swaps - OIS). We will omit government securities from our analysis as (i) this product represents a single borrower (and therefore a specific credit and term risk premium), while the other investigated interest rates are a product of the market forces forming the price for a nonspecified borrower among the banks' participants; and (ii) a bank willing to raise funds on the market by selling a government security can do so only if it has some in its portfolio, i.e. such fund raising is not unrestricted.

\subsection{Market for deposits}

The Czech National Bank (CNB) carries out regular surveys of the activity on the Czech interest rate market. Active residential banks are asked to provide their average daily turnovers for specified products and maturities traded with other banking counterparties (resident and non-resident - trades with the CNB are excluded). This survey is carried out four times a year now and the duration of the surveyed period is one week.

We have grouped the data into two main categories - (i) trades with maturity of up to 1 week inclusive and (ii) trades longer than 1 week. It is obvious at first sight that there is very little activity above the 1 -week horizon. If we look at more granular data ${ }^{3}$, we can see that on average $84 \%$ of the market volume is done on the $\mathrm{O} / \mathrm{N}$ market, and $97 \%$ of the market volume is traded in the time bucket covering maturities from 1 day to 1 week inclusive. We guess that there is a minimal number of trades done with maturity above the 1 day period, as the $1 \mathrm{~W}$ bucket also covers other types of 1 day maturities, T/N and $\mathrm{S} / \mathrm{N}$. The greatest part of the remaining trades above the 1-week horizon consists of trades done with non-resident banks, which we assume to be trades with the bank customers of the resident banks (i.e. trades with settlement through the loro account).

2 The market convention is to call the product a deposit from the perspective of both counterparties, although it is obvious that for one of them the cash flow represents a loan.

3 The CNB diversified the number of observed maturities into 6 time buckets from October 2007. 
Fig. 1: Interbank deposit market in CZK mil. and percentage of trades over $1 \mathrm{~W}$ (average daily turnovers)

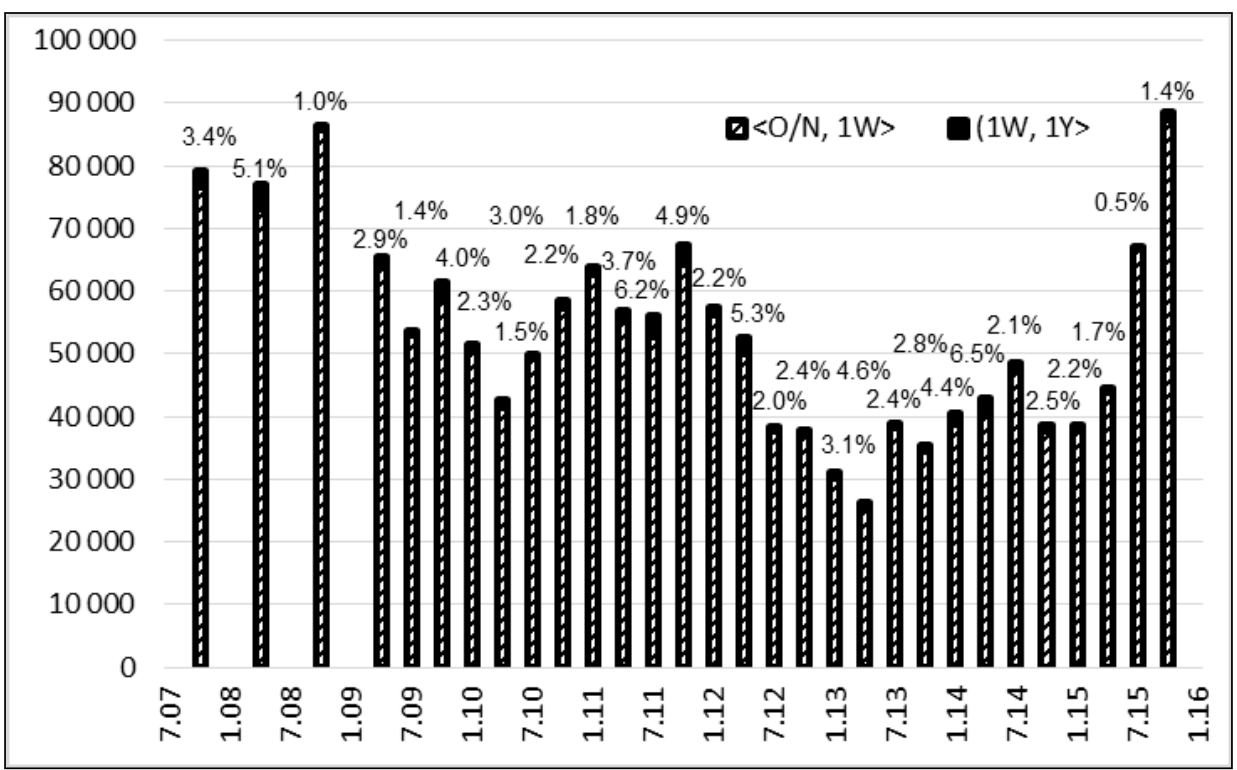

Source: CNB, authorial calculation.

The statistics before 2007 show data grouped only into 2 main categories - trades with maturity up to 3 months (inclusive) and trades above this period. We could see that even before the global financial crisis, the ratio of the longer dated trades was very low (around $2 \%$ of total volumes), however this share dropped even further after the market turmoil and it reached zero for 7 out of the last 10 observations (July 2013 - October 2015).

The overview demonstrates what the market practitioners would certainly confirm: there is no real deposit market for CZK. The only exception is the shortest end of the yield curve, where the market participants meet to manage their instantaneous liquidity needs. The price levels in the form of officially fixed market yields (PRIBOR) are in no way affiliated to the real market. These figures are, rather, guesses of the contributing banks based on their feelings - what the market could look like if there were one.

\subsection{Foreign exchange swaps}

Despite its name, an FX swap is a typical interest rate product. In an FX swap we receive a certain amount of one currency for a certain period and at the same time we place a certain amount of the other currency for the same period. Thus FX swaps can also be perceived as a combination of a deposit (in currency 1) and a 
loan (in currency 2). The price of the FX swap (called swap points) is a product of the interest rate differential between the currencies involved. ${ }^{4}$

The most common use of an FX swap can be summarized as follows:

- hedging the interest rate exposure and liquidity management,

- speculation on the interest rate development

- arbitraging between other money market products (e.g. deposit, OIS, short term FRA and IRS),

- calculating the FX forward price (this consists of the FX spot rate and FX swap points).

After this concise specification of the product, we shall have a deeper look at the situation on the Czech market. Like the surveys presented in the previous chapter, the CNB also collects data about the volumes traded in this product by active residential banks. In the CNB's overview the volumes done in FX swaps and FX forwards are shown as a single number, which is not a hiccup, as the materiality of the interest rate part of an FX forward perfectly matches the materiality of an FX swap. Unfortunately, there is no division into different maturity buckets in these overviews.

The basic indication of the maturity division of this product can be obtained from another survey carried out by the CNB on behalf of the BIS (Bank for International Settlements in Basel). This one is carried out every 3 years and covers trading activity for the FX and derivatives market in a chosen reporting month (typically April). With regard to FX swap trading we can see that again it is the shortest end of the yield curve which attracts the majority of the market activity. However, the time bucket covering maturities from 1 week to 1 year absorbs on average no less than $22 \%$ of the total volume. ${ }^{5}$

4 In reality there is also a small FX risk connected to FX swap pricing. It arises from the fact that the notional of one currency (base currency) is fixed for both value dates (spot and forward), and the full interest rate differential is applied only to the notional of the second currency. This creates a residual FX position called an FX tail. However, it can be effectively hedged by the swap counterparts.

5 In the BIS surveys the volumes against banking counterparties and against customers are mixed together, so we apply a simplifying conjecture that the division into maturity buckets is similar for both the customer and the interbank trades. 
Fig. 2: FX swap market in CZK mil. (average daily turnovers)

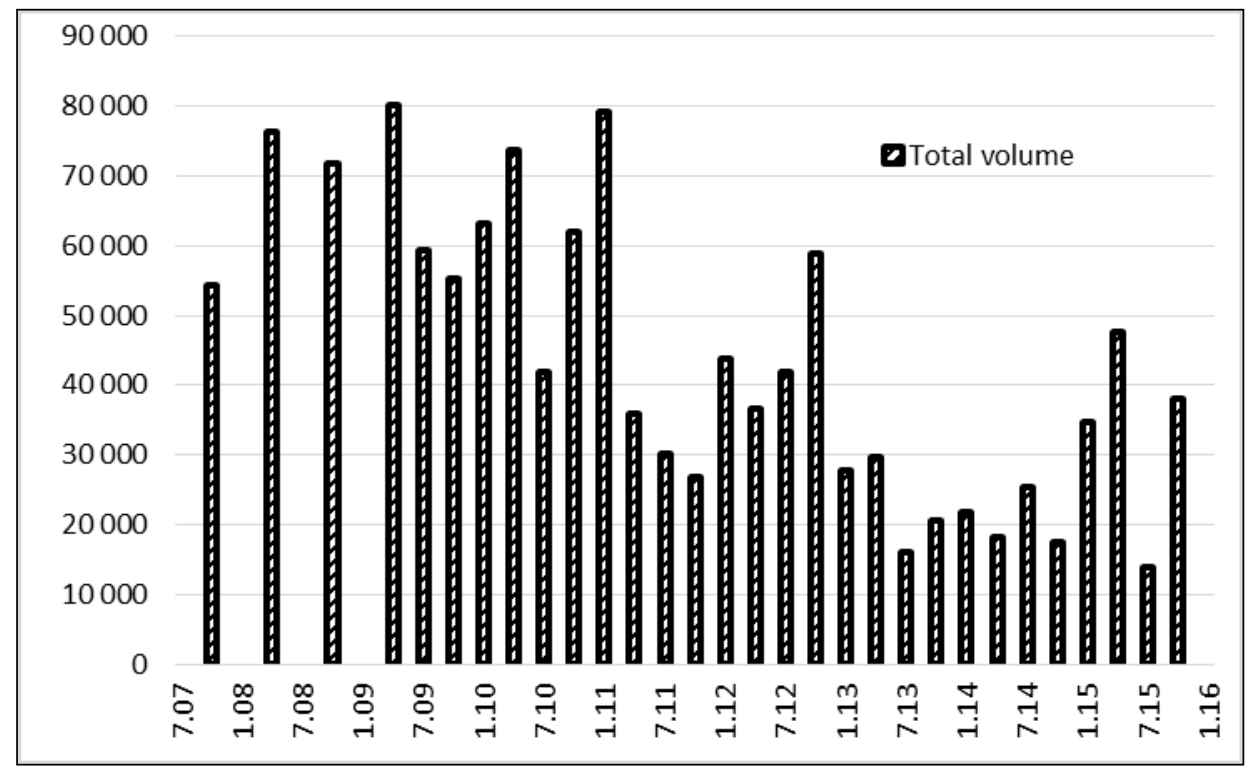

Source: CNB, authorial calculation.

Fig. 3: FX swap market: percentage of trades over $1 \mathrm{~W}$ and 1Y

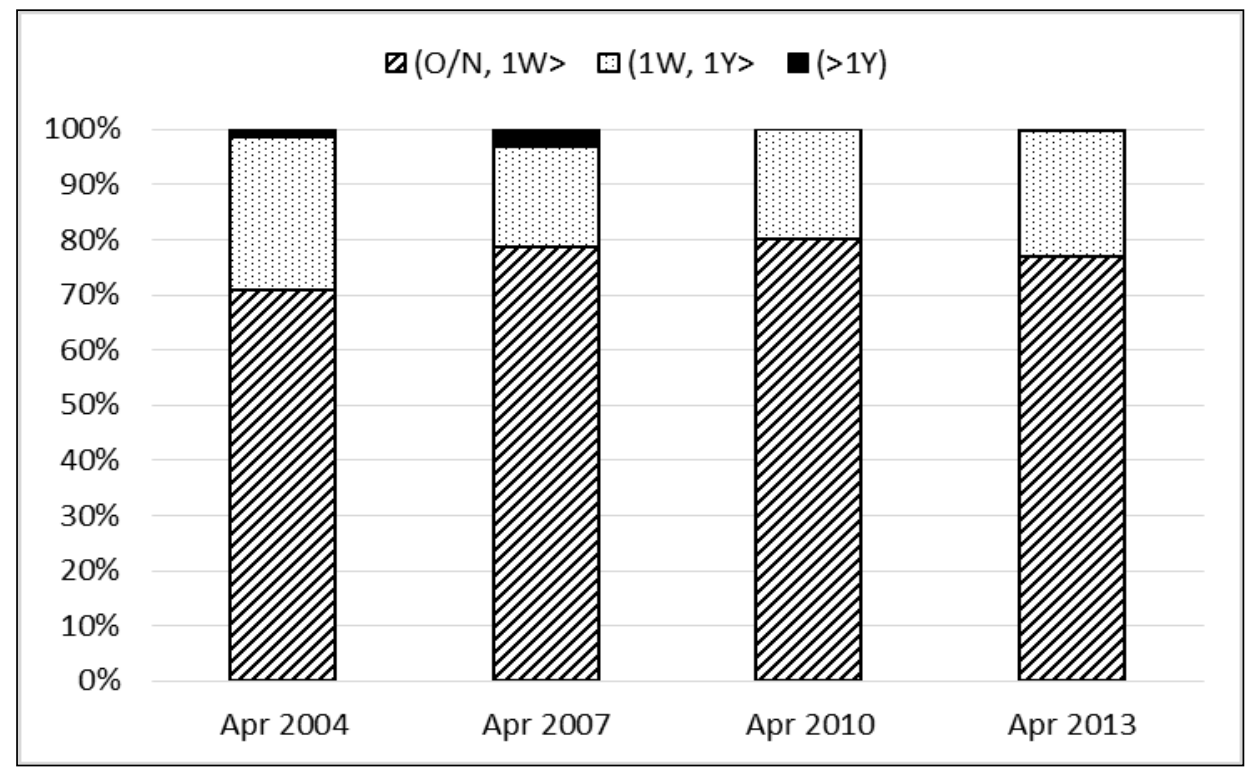

Source: BIS, authorial calculation. 
Although the volumes traded on the deposit and FX swap market are fairly comparable, it seems to be apparent that it is only the FX swap market which also attracts activity in the longer-term maturities. The market practitioners can confirm that we are stating the obvious. FX swap remains the source of CZK cash liquidity for all kind of longer dated trades. However, compared with the situation before the global financial crisis, the liquidity has substantially diminished.

Still, the CZK interest rates quoted through FX swaps are achievable and tradable. To what extent the rates are comparable with the artificially quoted deposit yields will be examined later in section 3 .

\subsection{Repos and derivatives}

The CNB is using the two-week (2W) repo tender as its main monetary policy instrument. Although these repo tenders are heavily used by local banks, and therefore this instrument is well known to the market participants, the interbank repo market is not developed. According to CNB surveys, the volumes traded on the Czech interbank market are negligible (typically less than $1 \%$ of the deposit volume).

Forward rate agreements (FRA) used to be a popular basic derivative traded on the Czech market. However, the volumes shown in the surveys in recent years often drop to zero. We think there are two main reasons behind this low activity:

- the low and stable interest rate environment, which does not encourage hedging and trading activities (speculations),

- few opportunities to arbitrage between the derivative and cash market.

On the other hand, the market in interest rate swaps (IRS) seems to have been stable throughout the recent challenging years. The typical daily volume is between 2 and 3 billion CZK, while the most common maturity lies between 2 and 10 years. This product is used by the banks to hedge their interest rate exposure arising mainly from their activities with the bank customers.

\section{Interest rates transmission}

In this section we will examine the conjunctions between the interest rates quoted on the interbank market and the interest rates provided by banks to their retail customers. The pricing relationship between those two markets is regularly investigated by researchers with the aim of identifying to what extent the wholesale rates pass through to the retail ones.

Another channel of interest rate transmission, which it is crucial to investigate, especially from the monetary policy perspective, is the pass-through of the central bank's policy interest rate into the retail lending and deposit rates of commercial 
banks. The ordinary perception of interest rate transmission sees the marketplace as the central point in the process. Firstly, the policy rate is supposed to be transformed into the yield curve by the wholesale market participants, who then use the curve information as the main source for assessing their cost of funding. As will be demonstrated later, the mechanism is not working so plainly any more. The onset of the financial crisis resulted in the break-up of those pass-through relationships. While the short end of the interest rate yield curve still seems to be tightly connected with the main policy rate(s), the longer end is mainly driven by newly established credit and term risk premiums. Secondly, the disappearing liquidity from the interbank market is preventing the commercial banks from using the marketplace as the source for their interest rate pricing. ${ }^{6}$

The markets have faced a lot of challenges during the last 10 years - the housing bubble, credit crisis, public debt crises, deflation and currency wars. All these factors have great implications for forming the market rates and, concurrently, the rates quoted to the bank customers. To have a fundamental view of the relationship on the Czech market, we will now develop a parsimonious model, which will help us to assess the basic conjunctions.

\subsection{Data}

As our main focus remains on the money market, we have chosen the $3 \mathrm{M}$ interest rate as the interbank base rate. In the first section it was demonstrated how illiquid the Czech deposit market is, so apart from the official product of the market, the 3M PRIBOR, we will calculate also an implied CZK FX swap yield using the standard swap rate formula:

$$
\text { SwapPips }=\operatorname{Spot} \times\left(\frac{1+r_{C Z K} \times \frac{t}{B_{V}}}{1+r_{E U R} \times \frac{t}{B_{B}}}-1\right),
$$

where SwapPips is price of the 3M EURCZK FX swap; Spot is actual EURCZK spot rate; $r_{C Z K}$ means CZK interest rate p.a. in decimals; $\quad r_{E U R}$ means EUR interest rate p.a. in decimals; $t$ is used for number of days and $\quad B_{V} / B_{B} \quad$ expresses basis of the variable/base currency.

By using the ask swap price and EURIBOR as the reference EUR yield, the calculated implied CZK yield should materially be a good gauge of the market CZK yield and comparable with the deposit market yield.

6 We investigate primarily the money markets. Gambacorta and Marques-Ibanez (2011), in contrast, report increased reliance of the banks on market sourced funding, having, primarily, the capital markets in mind. 
To assess the monetary policy pass-through, we will use the main policy rate of the Czech central bank ( $2 \mathrm{~W}$ repo rate) as the autonomous factor, while CZEONIA $^{7}, 3 \mathrm{M}$ PRIBOR and an implied 3M swap yield will be the dependent variables.

The more problematic part is to gather quality data showing the interest rates applied on the customer deposits and loans. Ideally, the maturity of the customer's contract should be in line with the maturity of the interbank one. Unfortunately, the standardized monetary statistics are not that granular.

From the data available we have selected loans based on the floating interest rate and interest rate fixed for a maximum of 1 year. The loans are provided in CZK to non-financial corporate customers by Czech banks according to the host country principal (i.e. the reporting institutions are Czech residents). The loans are further split into 3 categories according to the notional amount of each loan. Assuming that the pricing conditions of the largest loans will be most aligned with the market, the category with the highest loan amounts (i.e. exceeding 30 billion CZK) has been chosen.

On the retail deposit side, we will examine the interest rate applied on the current accounts and term deposits with contractual maturity up to 1 year. Both are related to non-financial corporate clients.

Data was collected for a full 10 year period starting in Jan 2006 and ending in December 2015 (incl.). Each observation is equal to 1 calendar month and the observed rates are expressed as monthly averages.

\subsection{Model}

Usually the initial visual assessment of the time series already indicates, how tight the relationship between the rates investigated is. According to Rousseas (1985), the lending rates of banks are the total of the cost of funds and an interest rate spread, which is called a mark-up or margin. This spread varies as time goes on. While Rousseas (1985) examines the relationship between the Federal Funds rate and banks' prime rates to assess the development of the mark-up, we will generalize his approach to any series of two related interest rates with the assumption that one of them is serving as a base (or reference rate) to originate the other (in the form of the reference rate plus the spread).

7 CZEONIA (Czech Overnight Index Average) is calculated as the weighted average of the interest rates of all unsecured $\mathrm{O} / \mathrm{N}$ deposits placed by reference banks on the interbank market. Thus it is a rate based on real trades. 
Based on these assumptions, we can describe the relationship between two interest rates using a parsimonious regression equation: ${ }^{8}$

$$
r_{t}^{D}=\alpha+\beta r_{t}^{R}+\varepsilon_{t},
$$

where $r_{D}$ is derived (dependent) rate; $r_{R}$ means reference rate; $\alpha, \beta$ are regression coefficients and $\varepsilon$ is used for residual disturbance.

By imagining homogenous pricing across the banks (the same margin for all customers constant over the period of time), the solution of the equation would result in $\alpha$ equal to the constant margin and $\beta$ equal to 1 , which means the passthrough of the reference rate is perfect.

\subsection{Pass-through of the policy rate}

As a first step we will investigate the linkage between the main policy rate and the market. ${ }^{9}$ Our focus remains on the short end of the curve, so the market rates will be represented by $\mathrm{O} / \mathrm{N}$ and $3 \mathrm{M}$ rates (Fig. 4). By solving the equation (2) by the OLS regression method we receive the coefficients $\alpha$ and $\beta$ presented in Tab. 1.

\section{Fig. 4: Development of the $2 \mathrm{~W}$ repo rate and the market rates (\% p.a.)}

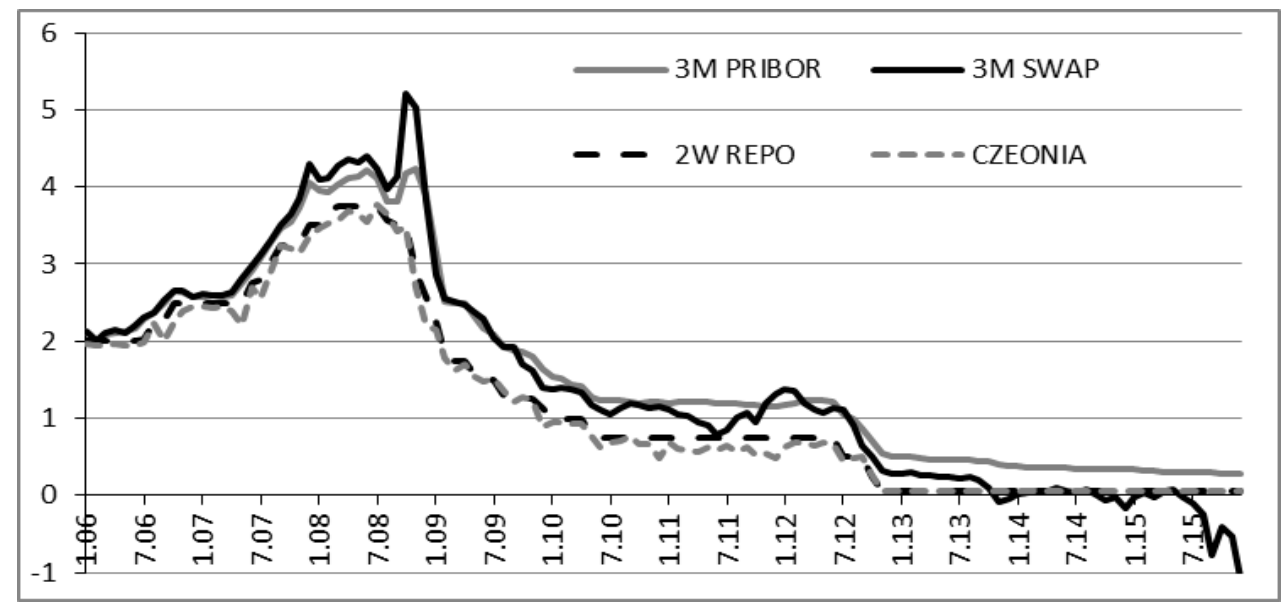

Source: Thomson Reuters, CNB, authorial calculation.

8 The pass-through relationship is usually analyzed by an advanced equation of an error correction model. However, in our data set the precondition for such a model, the cointegration of both time series is not fulfilled for all the examined series (especially in the case of the lending rates). For the sake of consistency and simplicity we will use the same model for all our calculations. When appropriate, the short term effects will be checked by splitting the time series into shorter periods of time.

9 For advanced research on the repo and PRIBOR relationship refer to Brada and Brůna (2004) and Mandel and Tomšík (2014). 
Staniek, D.: The Czech Crown Money Market as the Source for Pricing CustomerCcash Products.

Tab. 1: Pass-through of the policy rate

\begin{tabular}{lrrrrr}
\hline Dependent $\sim$ Reference Rate & & Coefficient & Std. Error & Probability & R-squared \\
\hline \multirow{2}{*}{ CZEONIA $\sim$ 2W REPO } & $\alpha$ & -0.03 & 0.010 & 0.002 & 0.99 \\
& $\beta$ & 0.97 & 0.006 & 0.000 & \\
\hline \multirow{2}{*}{ 3M PRIBOR $\sim$ 2W REPO } & $\alpha$ & 0.39 & 0.027 & 0.000 & 0.97 \\
\hline \multirow{2}{*}{ 3M SWAP $\sim$ 2W REPO } & $\beta$ & 1 & 0.015 & 0.000 & \\
& $\alpha$ & 0.07 & 0.043 & 0.100 & 0.95 \\
\hline
\end{tabular}

Source: authorial calculation.

The $2 \mathrm{~W}$ repo rate pass-through into the $\mathrm{O} / \mathrm{N}$ rate CZEONIA and $3 \mathrm{M}$ PRIBOR seems to be perfect with $\beta$ equal to 0.97 and 1 respectively. Both coefficients passed the reliability test (rejecting the null hypothesis of a zero coefficient at $5 \%$ confidence level) and according to the R-squared statistic the model is satisfactorily explanatory. The pass-through into the $3 \mathrm{M}$ swap yield seems to work long-term. However, there are periods of time, which contribute to the worse model statistics. Increased tension and uncertainty made the $3 \mathrm{M}$ swap yield rise over 3M PRIBOR during 2008, peaking in October 2008, when the average monthly difference reached 100 bps. Since mid-2012 the permanent deviation of the swap yield from the PRIBOR rate has begun. In 2012 the Czech central bank delivered 3 rate cuts of its main $2 \mathrm{~W}$ repo rate (from $0.75 \%$ to current $0.05 \%$ ), which were almost fully reflected in the decrease of $3 \mathrm{M}$ PRIBOR. However, the market swap yield dropped by an additional $0.20 \%$. With the start of the central bank's FX intervention regime in autumn 2013, the market, flooded with tremendous crown liquidity, pushed the swap yield below zero for the first time in its history. The interventions resumed in the middle of 2015 and the fresh liquidity pushed the yield far more into negative territory.

Having confirmed satisfactory pass-through channels between the policy rate and market rates, we will now examine if the relationships also work in the next phase, which is the pass-through of market rates into the lending and deposit (funding) rates quoted to the bank customers.

\subsection{Rates on customer deposits}

With a less developed capital market, deposits remain the primary source of funding for the Czech banking sector. Fig. 5 captures the development of the short term funding rates the banks have experienced in the last 10 years. Funding costs based on customer deposits are represented by the development of interest rates applied to customers' current accounts (CA) and rates applied to customer deposits with maturity of up to 1 year. The possible interbank funding is represented by 
CZEONIA, 3M PRIBOR and implied 3M swap yield. Tab. 2 and 3 summarize the observed pass-through relationship between those two funding sources. In other words, it explains whether the market rates serve as a reference rate for setting the rates to the bank customers.

Fig. 5: Development of the customer deposit rates and the market rates (\% p.a.)

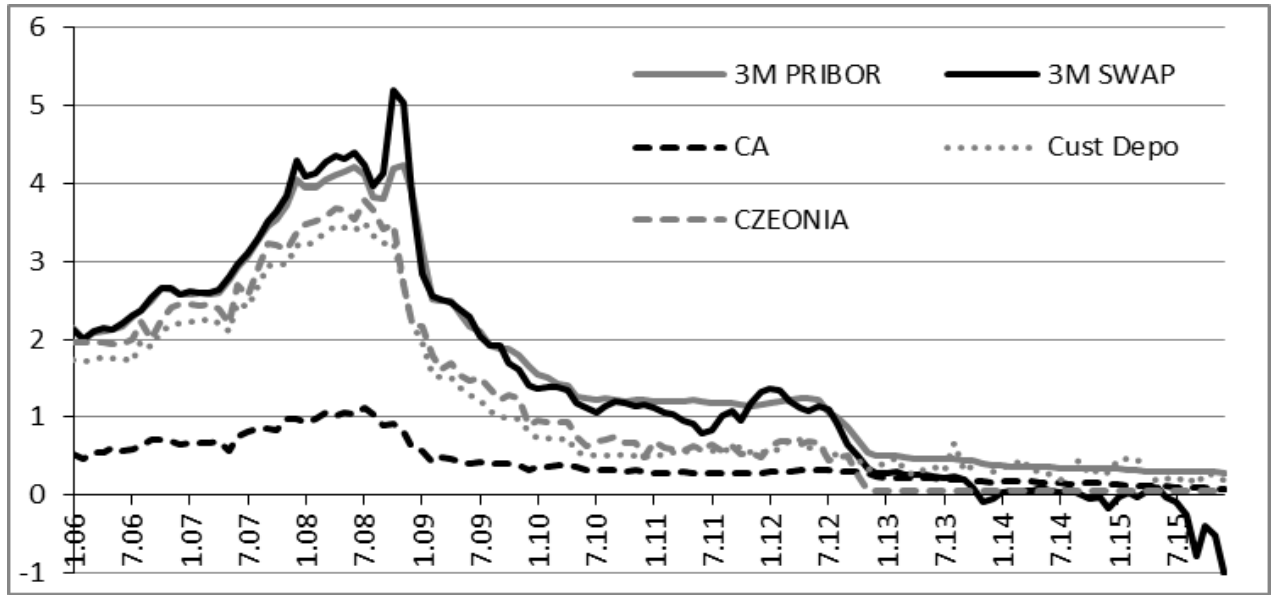

Source: Thomson Reuters, CNB/ARAD, authorial calculation.

Tab. 2: Pass-through of the market rates into the current account rates

\begin{tabular}{lcrrrr}
\hline Dependent $\sim$ Reference Rate & & Coefficient & Std. Error & Probability & R-squared \\
\hline \multirow{2}{*}{ CA CZEONIA } & $\alpha$ & 0.14 & 0.006 & 0.000 & 0.97 \\
& $\beta$ & 0.23 & 0.004 & 0.000 & \\
\hline \multirow{2}{*}{ CA 3M PRIBOR } & $\alpha$ & 0.06 & 0.010 & 0.000 & 0.94 \\
\hline \multirow{2}{*}{ CA 3M SWAP } & $\beta$ & 0.22 & 0.005 & 0.000 & \\
\hline SOurce: authorial & $\alpha$ & 0.14 & 0.010 & 0.000 & 0.93 \\
\hline
\end{tabular}

Source: authorial calculation. 
Staniek, D.: The Czech Crown Money Market as the Source for Pricing CustomerCcash Products.

Tab. 3: Pass-through of the market rates into the customer deposit rates

\begin{tabular}{lcrrrr}
\hline Dependent $\sim$ Reference Rate & & Coefficient & Std. Error & Probability & R-squared \\
\hline \multirow{2}{*}{ CUST DEPO $\sim$ CZEONIA } & $\alpha$ & 0.16 & 0.019 & 0.000 & 0.98 \\
& $\beta$ & 0.86 & 0.012 & 0.000 & \\
\hline \multirow{2}{*}{ CUST DEPO 3M PRIBOR } & $\alpha$ & -0.15 & 0.040 & 0.000 & 0.94 \\
\hline \multirow{2}{*}{ CUST DEPO $\sim 3$ M SWAP } & $\beta$ & 0.81 & 0.020 & 0.000 & \\
\hline
\end{tabular}

Source: authorial calculation.

At first glance it is obvious that the current account rates are not closely tied up with the market ones. As expected, CZEONIA is the market rate with the closest relationship to the current account yields. However, it is evident that the customer rate is not usually constructed as a fixed mark-up over CZEONIA. Banks exploit the higher market rates to increase their margins over $\mathrm{O} / \mathrm{N}$ rates, and once the $\mathrm{O} / \mathrm{N}$ rates start to fall, the decrease in current account rates is much less progressive. Since the middle of 2012 banks have paid even more than CZEONIA for retaining the demand deposits in house. The reason is clear - banks use this cash as funding even for their long-term lending. Internal deposit modelling allows that.

CZEONIA is also the most explanatory rate in pricing the longer-term customer deposits with maturities of up to 1 year. Negative $\alpha$ in the case of 3M PRIBOR signals that the construction of these rates is, rather, the reference rate minus a margin (which makes sense once PRIBOR is an offer rate), but again, for the last 3 years there have been some months in which the rate on customers' accounts surpassed the PRIBOR. There is not much room left for the banks to reduce the deposit rates further. The banks cannot follow the recent drop of the real market rates (swap rates) below zero, if they do not want to lose this source of funding.

\subsection{Lending rates}

The interest rate channel and bank lending channel are considered to be crucial parts of the monetary transmission mechanism. We have already confirmed that the central bank is able to control the market interest rates to a great extent. To have the transmission completed successfully, we need the market rates to behave as the determinant of the customers' borrowing costs.

We have separately assessed the pass-through of the 3M PRIBOR and 3M swap rate into the bank lending rates (as defined in chapter 3.1), first for the whole period 2006-2015 and then also for time periods separated into 5 blocks, each 
consisting of 24 monthly observations ( 2 full calendar years). The time series development and the results of the model are summarized in Fig. 6 and Tab. 4.

Fig. 6: Development of the lending rates and the market rates (\% p.a.)

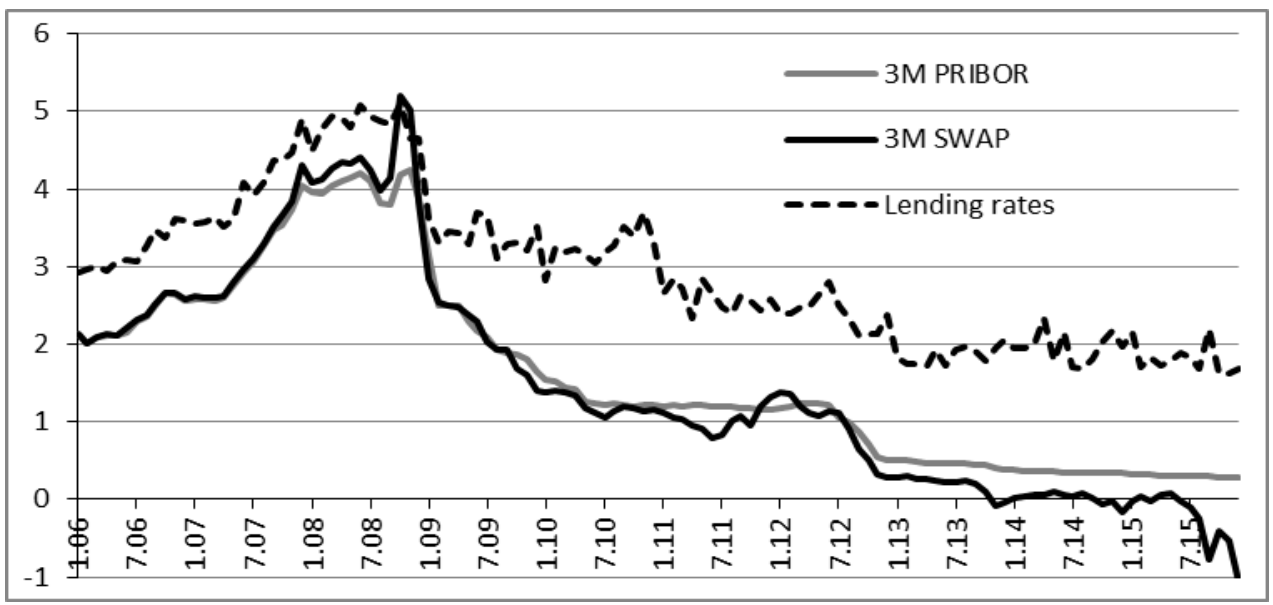

Source: Thomson Reuters, CNB/ARAD, authorial calculation.

Tab. 4: Pass-through of the market rates into the lending rates

\begin{tabular}{|c|c|c|c|c|c|c|c|c|c|}
\hline & & \multicolumn{4}{|c|}{ Lending Rates 3M PRIBOR } & \multicolumn{4}{|c|}{ Lending Rates $\sim 3$ M SWAP } \\
\hline & & Coef. & Std. Err. & Prob. & R-sqr. & Coef. & Std. Err. & Prob. & R-sqr. \\
\hline \multirow{2}{*}{ 2006-2015 } & $\alpha$ & 1.69 & 0.043 & 0.000 & \multirow{2}{*}{0.92} & 1.96 & 0.039 & 0.000 & \multirow{2}{*}{0.91} \\
\hline & $\beta$ & 0.77 & 0.020 & 0.000 & & 0.65 & 0.019 & 0.000 & \\
\hline \multirow{2}{*}{$2006-2007$} & $\alpha$ & 1.03 & 0.106 & 0.000 & \multirow{2}{*}{0.97} & 1.18 & 0.105 & 0.000 & \multirow{2}{*}{0.96} \\
\hline & $\beta$ & 0.95 & 0.038 & 0.000 & & 0.88 & 0.037 & 0.000 & \\
\hline \multirow{2}{*}{$2008-2009$} & $\alpha$ & 1.88 & 0.166 & 0.000 & \multirow{2}{*}{0.90} & 2.21 & 0.156 & 0.000 & \multirow{2}{*}{0.89} \\
\hline & $\beta$ & 0.72 & 0.051 & 0.000 & & 0.59 & 0.045 & 0.000 & \\
\hline \multirow{2}{*}{$2010-2011$} & $\alpha$ & 1.42 & 0.887 & 0.123 & \multirow{2}{*}{0.12} & 1.69 & 0.504 & 0.003 & \multirow{2}{*}{0.22} \\
\hline & $\beta$ & 1.20 & 0.706 & 0.102 & & 1.10 & 0.444 & 0.022 & \\
\hline \multirow{2}{*}{$2012-2013$} & $\alpha$ & 1.53 & 0.081 & 0.000 & \multirow{2}{*}{0.75} & 1.82 & 0.060 & 0.000 & \multirow{2}{*}{0.67} \\
\hline & $\beta$ & 0.82 & 0.102 & 0.000 & & 0.56 & 0.084 & 0.000 & \\
\hline \multirow{2}{*}{$2014-2015$} & $\alpha$ & 0.80 & 0.454 & 0.092 & \multirow{2}{*}{0.21} & 1.90 & 0.045 & 0.000 & \multirow{2}{*}{0.03} \\
\hline & $\beta$ & 3.26 & 1.360 & 0.026 & & 0.12 & 0.142 & 0.423 & \\
\hline
\end{tabular}

Source: authorial calculation. 
Even through the $\beta$ coefficients received for the full period 2006-2015 (0.77 and 0.65 respectively) indicate an imperfect pass-through, they seem to be a good guess of the market to lending rates relationship. ${ }^{10}$ We received even more reliable results for the first 2 year block (2006-2007). Apparently, the working interbank markets served as a good background for setting the lending rates to bank customers. Quite surprisingly, the following 2 year period also shows a rather tight relationship, even though it was the time of the culminating financial crisis. Due to the subsequent sovereign debt crisis (2010-2011) the pass-through relationship broke down. The credit margins were rising even though the markets were receiving large stimuli from the central banks around the world. ${ }^{11}$

While the situation in 2012-2013 seems to be stabilizing according to the model statistics and their reliability, the introduction of ultra-low interest rates distorted the pass-through relationship to such an extent that for the years 2014-2015 the model is not able to explain much. While the 3M PRIBOR was descending slightly from levels around $0.40 \%$ to $0.30 \%$, the lending rates kept their volatility and moved in the corridor between $1.60 \%$ and $2.30 \%$. Part of that volatility must certainly be attributed to the fact that the average rate of the portfolio of newly drawn loans can be biased by an extraordinarily large loan with an extraordinary margin. If we were able to filter out these untypical drawings, the development of the lending rate would probably follow the pattern of PRIBOR further.

Like the previous results concerning the pass-through of the $3 \mathrm{M}$ swap rate, its changes are much less explanatory, especially since the introduction of the nearzero rate policy.

${ }^{10}$ Comparable coefficients were reported by Bernhofer and van Treeck (2013) in research covering countries within the euro area also for a period of 10 years (1999-2009). The reported passthrough for short-term business loans varied from 0.67 (Germany) to 1.11 (France). The passthrough is typically more complete for loans than for deposits, which is also confirmed by de Bondt (2005). The fact that our observation shows higher pass-through for deposits can be explained by the more homogenous attributes for a deposit in our data set. In the case of loans, one extraordinary observation can bias the average rate, as the total portfolio of new loans is relatively small compared to studies made for a larger market (e.g. the euro area).

11 Paries et al. (2014) reports both the breakdown of the interest rate pass-through of monetary policy together with the breakdown of the market and retail lending rates relationship. Increasing spreads between the rates on loans to non-financial firms and the overnight interbank rate in the Eurozone are disclosed also by Illes and Lombardi (2013), even though the pattern of the move is not homogenous across the countries - the rise in the spread in the US, UK and core Eurozone countries calmed down in 2012, while it stayed high in the euro area peripherals. 


\section{Conclusion}

Notwithstanding the market turbulences, low liquidity and uncommon economic environment, the Czech crown money market has still proved to be a reliable source of market prices during the last ten years. The transmission of the main monetary policy rate into the short-term market rates is more than satisfactory. The subsequent pass-through into the customer lending and borrowing rates seems to work in the long-term. However, in the periods of extraordinary market disruptions, the relationship breaks up, particularly in the case of lending rates.

The current environment of ultra-low interest rates is clearly a disruptive factor for the interest rate pass-through. The lowering of the customer deposit rates is limited if the banks do not want to lose that source of funding. The exchange rate intervention regime introduced by the Czech central bank has pushed the market interest rates into negative territory. This move was not fully followed up by the official fixing of the market rate, the PRIBOR. It seems the banks are, rather, quoting the PRIBOR according to their main source of funding (customer deposits) and according to the shortest traded period $(\mathrm{O} / \mathrm{N})$, which holds above zero due to the fact that local banks can exploit the deposit facility with the Czech central bank.

The situation for loan customers can get tricky in such a situation, because their PRIBOR based long-term loans do not get cheaper even though the real market rates (quoted through FX swaps) are much lower. Yet there is a systematic risk for the banks too - if they reduced their lending margin over the PRIBOR, relying on the market buffer, and the PRIBOR realigned with the real market, part of that margin (if not the whole) would be lost. However, as the PRIBOR is a tool in the hands of the banks, customers seem to get the shorter end of the stick in the deal.

\section{References}

Baran, J., Witzany, J., 2014. Konstrukce výnosovych křivek v pokrizovém období. Politická ekonomie 1, 67-99. DOI: 10.18267/j.polek.938.

Bernhofer, D., van Treeck, T., 2013. New Evidence of Heterogeneous Bank Interest Rate Pass-Through in the Euro Area. Economic Modelling 35, 418-429. DOI: 10.1016/j.econmod.2013.07.020.

Bianchetti, M., 2010. Two curves, one price. Risk 8, 66-72.

Brada, J., Brůna, K., 2004. Analýza citlivosti referenčních úrokových sazeb PRIBOR na změny repo sazby České národní banky. Politická ekonomie 5, 601621, DOI: $10.18267 / j$.polek.478. 
de Bondt, G. J., 2005. Interest Rate Pass-Through: Empirical Results for the Euro Area. German Economic Review 1, 37-78. DOI: 10.1111/j.14656485.2005.00121.x.

Gambacorta, L., 2008. How Do Banks Set Interest Rates? European Economic Review 5, 792-819.

Gambacorta, L., Marques-Ibanez, D., 2011. The Bank Lending Channel: Lessons from the Crisis. Working Paper Series No. 1335, European Central Bank.

Illes, A., Lombardi, M., 2013. Interest Rate Pass-Through since the Financial Crisis. BIS Quarterly Review, September 2013, 57-66.

Mandel, M., Tomšík, V., 2014. Monetary Policy Efficiency in Conditions of Excess Liquidity Withdrawal. Prague Economic Papers 1, 3-23. DOI: 10.18267/j.pep.470.

Paries, M. D. et al., 2014. The Retail Bank Interest Rate Pass-Through: The Case of the Euro Area During the Financial and Sovereign Debt Crisis. Occasional Paper No. 155, ECB.

Rousseas, S., 1985. A Markup Theory of Bank Loan Rates. Journal of Post Keynesian Economics 1, 135-144. DOI: 10.1080/01603477.1985.11489549. 